\title{
Factors associated with unmet need of family planning in Bihar, India: a spatial and multilevel analysis
}

\author{
Anita Pal ${ }^{1}$, Jeetendra Yadav ${ }^{2 *}$, Sunita $^{2}$, Kh. Jitenkumar Singh ${ }^{2}$
}

\author{
${ }^{1}$ IIPS, Mumbai, Maharshtra, India \\ ${ }^{2}$ ICMR-NIMS, Ansari Nagar, New Delhi, India
}

Received: 19 June 2018

Accepted: 24 July 2018

\author{
*Correspondence: \\ Dr. Jeetendra Yadav, \\ E-mail: jeetu.nims@gmail.com
}

Copyright: (C) the author(s), publisher and licensee Medip Academy. This is an open-access article distributed under the terms of the Creative Commons Attribution Non-Commercial License, which permits unrestricted non-commercial use, distribution, and reproduction in any medium, provided the original work is properly cited.

\begin{abstract}
Background: Many women in low and middle-income countries would like to limit or delay their pregnancy, but they do not enough access to consistent use of modern contraceptive methods. The concept of unmet need for family planning is focus to reproductive health policies, as it endures serious implications for the women, the child, family and the whole society. The aims of the study are to assess the spatial dimensions of extent of unmet need for family planning and also identify association between individual, household, community and district level covariates with the level of unmet need for family planning among married women of reproductive age group in Bihar, India.

Methods: The study uses data from fourth round of the National Family Health Survey (NFHS-4). To meet the objective the analysis included descriptive, spatial visualization, spatial autocorrelation and multilevel logistic model. In the first step of analysis the multivariate analysis was used to know the levels of unmet need for family planning by selected background characteristics.

Results: This study indicating that nearly one in five or more women experiences unmet need for family planning suggests that the problem remains of considerable magnitude and that action is needed to fill the gap in contraceptive use, which is currently estimated at a lowest 24 percent. Apart from providing a current estimate of unmet need, our study identified a number of relevant socioeconomic and demographic factors likely to shape the probability that a women experiences unmet need. It is observed across individual level, community/psu level and district level.

Conclusions: Considering this fact, family planning program in Bihar should also focus on eliminating misconceptions and fear about contraception through proper counselling of couples and information, education and communication activities in the community and try to improve the quality of advice and care services related to family planning.
\end{abstract}

Keywords: Family planning, Unmet need, Spatial and multilevel analysis

\section{INTRODUCTION}

Many women in low and middle-income countries would like to limit or delay their pregnancy, but they do not enough access to consistent use of modern contraceptive methods. ${ }^{1,2}$

These women are experiencing an unsatisfied demand for contraception which is commonly known as unmet need for family planning. The concept of unmet need for family planning is focus to reproductive health policies, as it endures serious implications for the women, the child, family and the whole society. 3,4

In many countries, unmet need for family planning among pregnant women is a main reason of closely spaced births, child bearing at a very early age, unsafe 
abortions or physical abuse, all of which are considered as main cofactors to high maternal and infant mortality. ${ }^{3-6}$

More than one in ten married or in-union women worldwide experience an unmet need for family planning; that is to articulate, they affirm that they want to stop or delay childbearing but are not using any method of contraception to prevent pregnancy. ${ }^{7}$ The world fertility has declined steadily since the 1950 s, with major contributions from China and India. ${ }^{8}$ India is the one of the second largest country in the world in terms of population. This led to the declaration of the first-ever official family planning program in the world by the Government of India in 1952.

This program was obvious in the contour of the beginning of fertility decline in India in the first half of 1960s. However, some EAG states such as Rajasthan, Chhattisgarh, Madhya Pradesh, Uttar Pradesh, Bihar, Jharkhand are current fertility rates are still relatively high. ${ }^{9}$ According to several studies, contraception is one of the most important proximate determinants of fertility. ${ }^{10-12}$

Family Planning is being a feasible solution to control fast growing population, not only helps in spacing and limiting the number of children, but also improves maternal and child health. The unmet need for family planning is defined as the proportion of married women of reproductive age who are not using any method but would like to postpone the next pregnancy i.e. unmet need for spacing or who do not want any more children i.e. unmet need for limiting. ${ }^{13}$ Contraceptive continuation is considered to be a summary outcome indicator of the quality of family planning services. ${ }^{14-20}$

The causes may be due to many socioeconomic factors. Thus, here the concepts like KAP (Knowledge, attitudes, and practice) -gap came. ${ }^{21}$ Numerous studies have established clear relationship between women's age and the level of unmet need for both spacing and limiting.

Among older women most unmet need is for limiting because older women have had as many children as they want. It was found that the need for spacing begins to decline after age 30 , whereas the need for limiting peaks at age $35-44 .^{22}$ In the same study it was found that unmet need is lower in urban areas than in rural areas. The percentage of total demand that is unmet is especially high among rural women, illiterate women, women whose husbands are illiterate, muslim women, Scheduled tribe women and women not exposed to media messages on family planning. ${ }^{23}$

Objective of present study was to assess the spatial dimensions of extent of unmet need for family planning and also identify association between individual, household, community and district level covariates with the level of unmet need for family planning among married women of reproductive age group in Bihar, India.

\section{METHODS}

The study uses data from fourth round of the National Family Health Survey (NFHS-4), the Indian version of the Demographic and Health Survey (DHS).

The NFHS-4 sample is a stratified two-stage sample. The 2011 census served as the sampling frame for the selection of PSUs. PSUs were villages in rural areas and Census Enumeration Blocks (CEBs) in urban areas. Within each rural stratum, villages were selected from the sampling frame with probability proportional to size (PPS). For this study analysis considered 35443 currently married women from 1778 cluster (PSU) in 38 district of Bihar.

\section{Outcome measurements}

The outcome variable in this study was unmet need of family planning. According to NFHS-4 report, unmet need for family planning refers to fecund women who are not using contraception but who wish to postpone the next birth (spacing) or stop childbearing altogether (limiting). Specifically, women are considered to have unmet need for spacing if they:

- are not pregnant and not postpartum amenorrhoeic, are considered fecund, and want to postpone their next birth for 2 or more years or stop childbearing altogether, but are not using a contraceptive method, or

- have a mistimed or unwanted current pregnancy, or

- are postpartum amenorrhoeic and their last birth in the last two years was mistimed or unwanted.

\section{Defining predictor variables}

Consistent with the study objective and given the effect of the outcome variable, a range of individuals, community and district-level predictor variables were used based on theoretical and empirical importance applied in international literature and availability of the data in the dataset. The detailed of predictors variables are given below.

\section{Individual-level-variables}

The study considered a number of potential individual factors, included in the analysis were current age of women, birth order and birth interval, women's and husband's education, women's and husband's work status and mass media exposure.

\section{Community-level-variables}

This study included the following community level factors: Place of residence: urban or rural ,Community maternal unemployment rate (percentage of women not working in the community), Community maternal illiteracy rate (percentage of women with no formal 
education in the community), Community poverty (percentage of households below $20 \%$ of wealth index), female-headed households (Percentage of households headed by women in an area), Community institutional delivery (Percentage of institutional delivery in the community), Community maternal full ANC utilization (Percentage of women with full antenatal care during the pregnancy in the community).

\section{District-level-variables}

Proportion of urban population in the district, proportion of SC and ST in the district and female literacy in the district.

\section{Analytical approach}

To meet the objective the analysis included descriptive, spatial visualization, spatial autocorrelation and multilevel logistic model. In the first step of analysis the multivariate analysis was used to know the levels of unmet need for family planning by selected background characteristics while in the second part of the analysis the spatial analysis was used. In the spatial analysis, Moran's I statistic is used to assess global spatial auto correlation for unmet need for family planning across sample districts. The value of Moran's I range from -1 to 1 .

The Local Indicator of Spatial Association (LISA) effectively decomposes a global measure of spatial autocorrelation for each spatial unit, enabling assessment of statistical significance for each unit. ${ }^{25}$ In the third step of the analysis, a multilevel logistic regression model with three levels, individual and household (level 1), nested within communities (level 2), and communities nested within districts (level 3), was fitted to assess the influences of measured individual, community and district factors (fixed effects) on unmet needs for family planning. ${ }^{26-29}$

To know the multicollinearity among the predictor variables the Variance inflation factor (VIF) computed prior to inclusion the variables in multilevel model. Variance inflation factors (VIF) of each variable are computed to check collinearity prior to step-up in multilevel logistic regression model.

Problem of collinearity within predictors' variables not found. The highest Variance inflation factor (VIF) was 2.55. The whole analysis was performed using STATA version 13.0.

To take into account the survey design (i.e. sampling weights with clustering and strata) while estimating bivariate and multivariate statistics, the SVY command in STATA was used and spatial analysis is done using QGIS 3.0, ArcGIS 10.2 and GeoDa 1.12..$^{30-32}$

\section{RESULTS}

\section{Differentials in unmet need of family planning}

To identify the factors associated with the unmet need for family planning the bivariate differential by the selected individuals, household, community and district characteristics were examined.

Table 1 represents the weighted percentage of women who were facing the problem of unmet need for family planning. Unmet need for family planning among married women ranges low (9 percent) among women age 35-49 to a high (32 percent) among women age 15-24. More than one forth about 29 percent of unmet need for family planning among women who have 1 or 2 living children. Unmet need for family planning generally increases with increasing education, from 19 percent among illiterate women to 26 percent among those who have completed high school or above. Community with medium and high maternal unemployment has 19 percent unmet needs.

In the Figure 1, district wise percent of unmet need is displayed. The percentage of unmet need for family planning is categorized in three groups: 17 to 20,21 to 23 and 24 to 26 . Most of the districts have low ranges (17 to 20 percent) of unmet need for family planning. From the figure it is clear that south western districts have low unmet need. Unmet need for family planning is lowest in Buxar, Rohtas and Madehpura (17 percent each) and highest in Sheohar, Saran and samastipur (26 percent each).

Figure 2 univariate LISA cluster LISA significant maps for unmet need of family planning by district. To measure the extent of neighborhoods clustering in the use of unmet need across districts. Global Moran's and Local Indicator Spatial Autocorrelations (LISA) has been computed using rook's weight matrix and 999 permutations for randomization to observe univariate clustering and bivariate clustering.

The overall Global Moran's spatial autocorrelation index is computed 0.135 ( $\mathrm{p}$ value $=0.059$ ). LISA maps of spatial clustering and their significance map has been generated using the Geo-Da univariate LISA maps. Figure 2, 3 and 4 illustrate the spatial outliers, high-high clustering (in red color), low-low clustering (in blue color) which is greatly helpful in identifying the district with significant neighborhood clustering.

In the Figure 3, bivariate Morgan statistics taking poorest wealth percentage in the districts give high positive autocorrelation for unmet need with the Moran'I index value is 0.218 (0.002). Four district in the bivariate LISA cluster map indicated the high-high value $(\mathrm{p}<0.01)$. Considering figure 4, the Moran'I index value is 0.005 (0.420). 
Table 1: Percent distribution of unmet need for family planning by selected background characteristics, Bihar, India, NFHS-4 (2015-16).

\begin{tabular}{|c|c|c|c|}
\hline Background characteristics & Sample & Weighted proportion & $95 \% \mathrm{CI}$ \\
\hline \multicolumn{4}{|l|}{ Individual-level variables } \\
\hline \multicolumn{4}{|l|}{ Current Mother's age } \\
\hline $15-24$ & 8,853 & 31.5 & $(30.4-32.6)$ \\
\hline $25-30$ & 13,453 & 26.1 & $(25.2-27.0)$ \\
\hline $35-49$ & 13,137 & 9.1 & $(08.5-09.7)$ \\
\hline \multicolumn{4}{|l|}{ Number of living children } \\
\hline 0 & 4,183 & 16.2 & $(15.0-17.6)$ \\
\hline $1-2$ & 12,222 & 28.9 & $(28.0-29.9)$ \\
\hline $3-4$ & 13,503 & 17.3 & $(16.5-18.2)$ \\
\hline $5+$ & 5,535 & 17 & $(15.8-18.2)$ \\
\hline \multicolumn{4}{|l|}{ Mother's education } \\
\hline Illiterate & 19,765 & 19.1 & $(18.4-19.9)$ \\
\hline Literate but below primary & 2,139 & 21.2 & $(19.3-23.2)$ \\
\hline Primary but below middle & 1,920 & 24.5 & $(22.4-26.7)$ \\
\hline Middle but below high school & 8,098 & 23.0 & $(21.9-24.1)$ \\
\hline High school and above & 3,521 & 26.3 & $(24.6-28.1)$ \\
\hline \multicolumn{4}{|l|}{ Father's education } \\
\hline Illiterate & 1,894 & 21.9 & $(19.6-24.4)$ \\
\hline Literate but below primary & 301 & 17.7 & $(13.7-22.7)$ \\
\hline Primary but below middle & 807 & 22.5 & $(19.2-26.3)$ \\
\hline Middle but below high school & 777 & 23.4 & $(20.0-27.3)$ \\
\hline High school and above & 1,978 & 21.7 & $(19.6-23.9)$ \\
\hline \multicolumn{4}{|l|}{ Women's occupation } \\
\hline Not working & 4,664 & 22.9 & $(21.3-24.6)$ \\
\hline Agricultural work & 615 & 15.1 & $(12.4-18.3)$ \\
\hline Skilled/Unskilled work & 156 & 26.9 & $(19.4-35.9)$ \\
\hline Professional work & 323 & 17.8 & $(13.3-23.3)$ \\
\hline \multicolumn{4}{|l|}{ Husband's occupation } \\
\hline Not working & 542 & 22.6 & $(19.1-26.6)$ \\
\hline Agricultural work & 1,658 & 17.9 & $(15.8-20.1)$ \\
\hline Skilled/Unskilled work & 1,662 & 23.8 & $(21.3-26.4)$ \\
\hline Professional work & 1,896 & 23.6 & $(21.2-26.2)$ \\
\hline \multicolumn{4}{|l|}{ Mass media exposure } \\
\hline No exposure & 19,231 & 21.0 & $(20.2-21.7)$ \\
\hline Any exposure & 16,212 & 21.3 & $(20.6-22.2)$ \\
\hline \multicolumn{4}{|l|}{ Religion } \\
\hline Hindu & 30,063 & 19.9 & $(19.4-20.5)$ \\
\hline Non-Hindu & 5,379 & 28.0 & $(26.5-29.6)$ \\
\hline \multicolumn{4}{|l|}{ Social group } \\
\hline ST & 1,237 & 23.5 & $(20.7-26.5)$ \\
\hline $\mathrm{SC}$ & 7,039 & 21.2 & $(20.0-22.4)$ \\
\hline $\mathrm{OBC}$ & 21,109 & 20.7 & $(20.0-21.4)$ \\
\hline Others & 5,759 & 22.5 & $(21.2-23.9)$ \\
\hline \multicolumn{4}{|l|}{ Wealth quintile } \\
\hline Poorest & 17,813 & 22.2 & $(21.5-23.0)$ \\
\hline Poorer & 8,429 & 20.7 & $(19.7-21.7)$ \\
\hline Middle & 4,765 & 19.6 & $(18.4-20.9)$ \\
\hline Richer & 3,214 & 19.3 & $(17.7-21.0)$ \\
\hline Richest & 1,222 & 18.9 & $(16.0-22.4)$ \\
\hline \multicolumn{4}{|l|}{ Community-level variables } \\
\hline \multicolumn{4}{|l|}{ Type of residence } \\
\hline Urban & 4,396 & 19.1 & $(17.5-20.9)$ \\
\hline Rural & 31,047 & 21.4 & $(20.8-22.0)$ \\
\hline \multicolumn{4}{|c|}{ Community maternal unemployment rate } \\
\hline $0-25 \%$ & 24,712 & 21.2 & $(20.5-21.9)$ \\
\hline $25-50 \%$ & 5,221 & 19.8 & $(18.5-21.2)$ \\
\hline 51 and above & 846 & 19.1 & $(15.9-22.8)$ \\
\hline \multicolumn{4}{|c|}{ Community poverty (percentage of households below $20 \%$ of wealth index) } \\
\hline $0-25 \%$ & 7,081 & 19.2 & $(18.0-20.5)$ \\
\hline $25-50 \%$ & 10,578 & 21.3 & $(20.3-22.3)$ \\
\hline 51 and above & 17,783 & 21.8 & $(21.0-22.7)$ \\
\hline Total & 35443 & 21.1 & $(20.6-21.7)$ \\
\hline
\end{tabular}




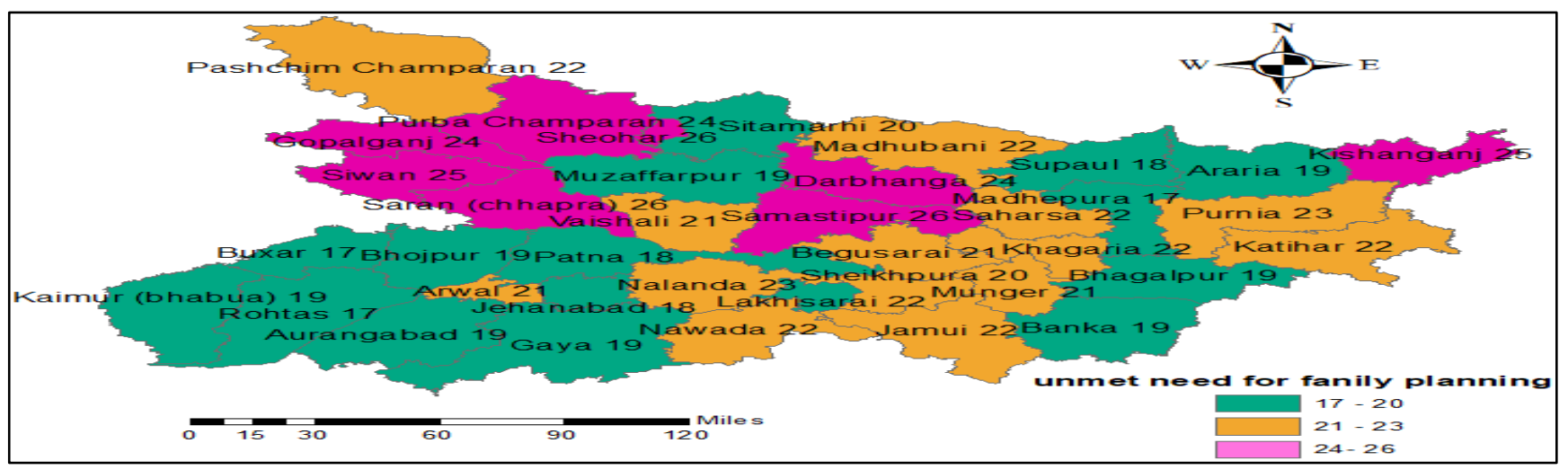

Figure 1: Proportion unmet need of family planning by district.

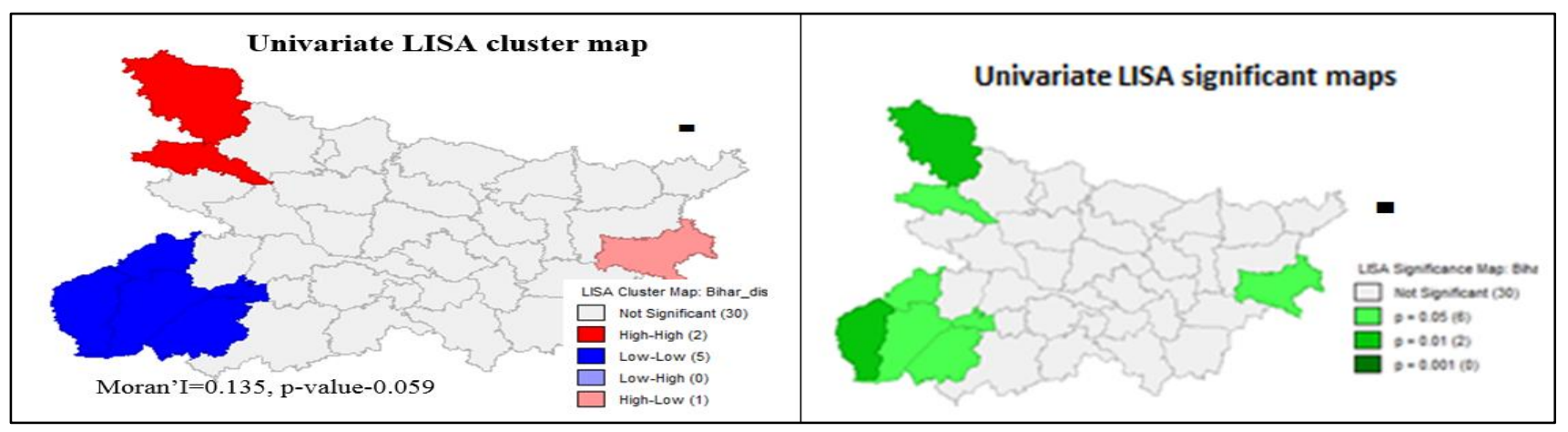

Figure 2: Univariate LISA cluster LISA significant maps for unmet need of family planning by district.

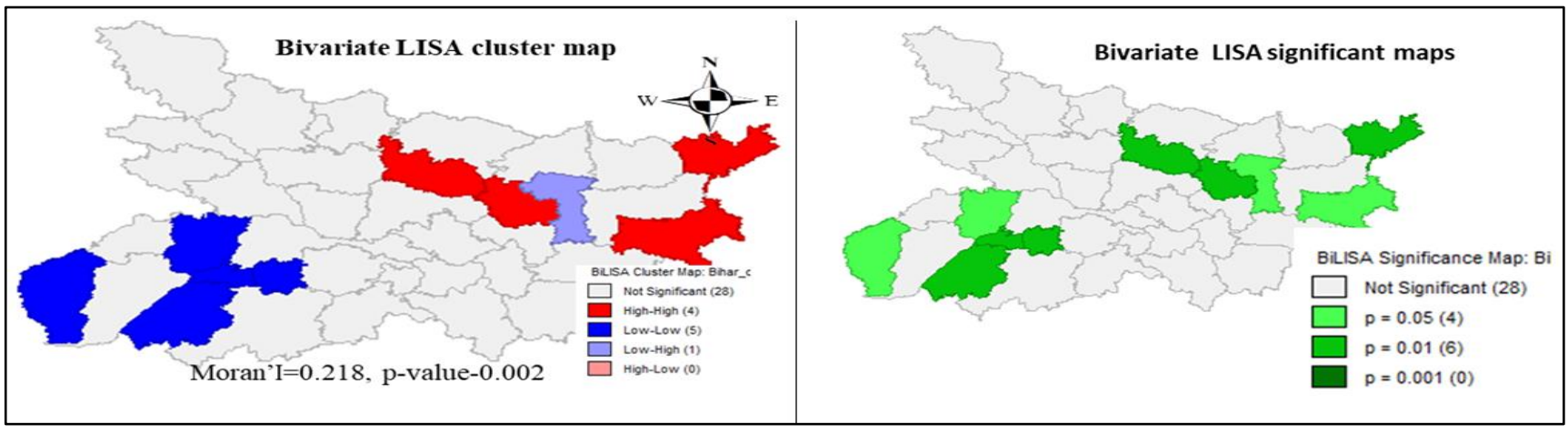

Figure 3: Bivariate LISA cluster and significant map for unmet need for family planning and district poorest wealth percentage.

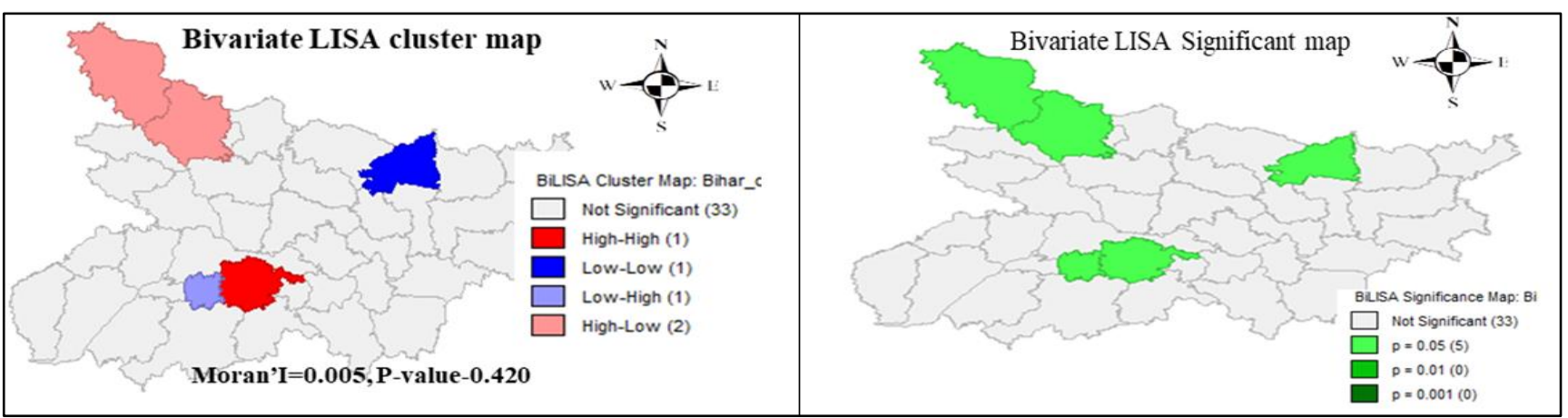

Figure 4: Bivariate LISA cluster and significant map for unmet need for family planning and district urban percentage. 
Table 3: Result of the multilevel analysis showing odds ratio with $95 \%$ CI and p-value for unmet need for family planning among currently married women by selected covariates, Bihar, India, NFHS-4 (2015-16).

\begin{tabular}{|c|c|c|c|c|}
\hline Background characteristics & Odds Ratio & SE & p-value & $95 \%$ C. I \\
\hline \multicolumn{5}{|l|}{ Individual-level variables } \\
\hline \multicolumn{5}{|l|}{ Current Mother's age } \\
\hline $15-24$ & 1.00 & & & \\
\hline $25-30$ & 0.087 & 0.146 & 0.145 & $(0.003-2.326)$ \\
\hline $35-49$ & 0.387 & 0.203 & 0.070 & $(0.139-1.082)$ \\
\hline \multicolumn{5}{|l|}{ Number of living children } \\
\hline 0 & 1.00 & & & \\
\hline $1-2$ & 0.086 & 0.056 & 0.000 & $(0.024-0.307)$ \\
\hline $3-4$ & 3.192 & 1.884 & 0.049 & $(1.004-10.153)$ \\
\hline $5+$ & 3.475 & 2.380 & 0.069 & $(0.907-13.306)$ \\
\hline \multicolumn{5}{|l|}{ Mother's education } \\
\hline Illiterate & 1.00 & & & \\
\hline Literate but below primary & 1.143 & 1.073 & 0.241 & $(0.463-4.351)$ \\
\hline Primary but below middle & 0.873 & 0.590 & 0.840 & $(0.232-3.287)$ \\
\hline Middle but below high school & 0.906 & 0.606 & 0.883 & $(0.244-3.362)$ \\
\hline High school and above & 1.193 & 0.504 & 0.677 & $(0.521-2.732)$ \\
\hline \multicolumn{5}{|l|}{ Father's education } \\
\hline Illiterate & 1.00 & & & \\
\hline Literate but below primary & 1.603 & 1.053 & 0.130 & $(0.685-2.966)$ \\
\hline Primary but below middle & 1.913 & 1.351 & 0.359 & $(0.479-7.638)$ \\
\hline Middle but below high school & 1.361 & 1.028 & 0.683 & $(0.310-5.981)$ \\
\hline High school and above & 2.423 & 1.485 & 0.149 & $(0.729-8.053)$ \\
\hline \multicolumn{5}{|l|}{ Women's occupation } \\
\hline Not working & 1.00 & & & \\
\hline Agricultural work & 1.194 & 0.543 & 0.696 & $(0.490-2.910)$ \\
\hline Skilled/Unskilled work & 2.627 & 1.158 & 0.028 & $(1.107-6.233)$ \\
\hline Professional work & 2.936 & 1.237 & 0.026 & $(1.108-7.256)$ \\
\hline \multicolumn{5}{|l|}{ Husband's occupation } \\
\hline Not working & 1.00 & & & \\
\hline Agricultural work & 0.326 & 0.210 & 0.082 & $(0.092-1.154)$ \\
\hline Skilled/Unskilled work & 0.879 & 0.523 & 0.828 & $(0.274-2.818)$ \\
\hline Professional work & 0.422 & 0.247 & 0.141 & $(0.134-1.331)$ \\
\hline \multicolumn{5}{|l|}{ Mass media exposure } \\
\hline No exposure & 1.00 & & & \\
\hline Any exposure & 2.517 & 1.048 & 0.027 & $(1.113-5.693)$ \\
\hline \multicolumn{5}{|l|}{ Religion } \\
\hline Hindu & 1.00 & & & \\
\hline Non-Hindu & 0.274 & 0.164 & 0.031 & $(0.085-0.887)$ \\
\hline \multicolumn{5}{|l|}{ Social group } \\
\hline ST & 1.00 & & & \\
\hline SC & 1.718 & 1.186 & 0.671 & $(0.142-20.801)$ \\
\hline OBC & 1.863 & 1.218 & 0.617 & $(0.163-21.348)$ \\
\hline Others & 2.622 & 2.347 & 0.450 & $(0.215-31.995)$ \\
\hline \multicolumn{5}{|l|}{ Wealth quintile } \\
\hline Poorest & 1.00 & & & \\
\hline Poorer & 0.703 & 0.344 & 0.471 & $(0.270-1.833)$ \\
\hline Middle & 0.850 & 0.482 & 0.774 & $(0.279-2.584)$ \\
\hline Richer & 0.575 & 0.388 & 0.413 & $(0.153-2.161)$ \\
\hline Richest & 0.729 & 0.723 & 0.750 & $(0.104-5.091)$ \\
\hline \multicolumn{5}{|l|}{ Community-level variables } \\
\hline \multicolumn{5}{|l|}{ Type of residence } \\
\hline Urban & 1.00 & & & \\
\hline Rural & 0.608 & 0.333 & 0.363 & $(0.208-1.777)$ \\
\hline \multicolumn{5}{|c|}{ Community maternal unemployment rate } \\
\hline $0-25 \%$ & 1.00 & & & \\
\hline $25-50 \%$ & 0.578 & 0.215 & 0.140 & $(0.279-1.197)$ \\
\hline 51 and above & 0.287 & 0.259 & 0.167 & $(0.049-1.687)$ \\
\hline \multicolumn{5}{|c|}{ Community poverty (percentage of households below $20 \%$ of wealth index) } \\
\hline \multicolumn{5}{|c|}{$0-25 \%$} \\
\hline $25-50 \%$ & 1.646 & 1.390 & 0.064 & $(0.945-7.410)$ \\
\hline 51 and above & 1.903 & 1.185 & 0.301 & $(0.562-6.446)$ \\
\hline
\end{tabular}


Table 3 shown odds ratio estimates from the multilevel logistic regression model. The model confirmed a positive association between unmet need for family planning and having three or four children $[\mathrm{OR}=3.192$; 95\% CI], women who have engaged in skilled/unskilled work $[\mathrm{OR}=2.627 ; 95 \% \mathrm{CI}]$ and professional work $[\mathrm{OR}=2.936 ; 95 \% \mathrm{CI}]$, women who having any media exposure $[\mathrm{OR}=2.517 ; 95 \% \mathrm{CI}]$. The model detected a negative association between unmet need for family planning and having one or two children [OR=0.087; 95\% CI], being non-Hindu [OR=0.274; 95\% CI]. The model did not detect any variance attributable at the community/psu level as well as district level.

\section{DISCUSSION}

This study is based on currently married women from nationally representative survey, which attempted to determinants of unmet need and their variation in the state of Bihar. It emerges that this could be attributed to poor performance of family planning program in Bihar. It has failed to provide people with enough choices and range of contraceptives for spacing. The family planning program in Bihar like many other states in India has primarily focused on sterilization. There has been little incentive for program managers or grass root health workers to promote contraceptive methods for spacing. ${ }^{33}$ Thus, it is not surprising that pregnancies still go unplanned. The overall unmet need for family planning remains substantially high in Bihar.

This study indicating that nearly one in five or more women experiences unmet need for family planning suggests that the problem remains of considerable magnitude and that action is needed to fill the gap in contraceptive use, which is currently estimated at a lowest 24 percent. ${ }^{9}$ Sheohar, Saran and Samastipur were found highest percentage of unmet need of family planning. Women with unmet need for family planning usually the focus of family planning programs because they exhibit a discrepancy between their fertility intentions and contraceptive use. ${ }^{34,35}$ Unmet need have some important consequences for a women and her family, including unwanted pregnancies, unsafe abortions, and poor maternal health outcomes. Basically, overcoming unmet need is likely to result in significant improvements in women's health while also limiting further population growth which is very important to overcome some challenges towards sustainable development. ${ }^{3,36}$ Therefore, the strong odds for women with more than one child should not come as a surprise. ${ }^{37}$ Religious prohibition is the one of the main reasons for not using family planning. In this study finding suggests that the unmet need for family planning among NonHindu women is much higher than Hindu women in Bihar. With the help of information and communication activities it is possible to increase the level of contraception use. $^{38}$ There is significant association between unmet need for family planning and mass media exposure.

\section{CONCLUSION}

Unmet need is an important concept for family planning programs. It is one of the immediate objectives of the National Population Policy of Government of India (NPP, 2000). However, unmet need in the states like Bihar is still very high. The Government of India and specially that of Bihar will have to take immediate steps to address the causes of high unmet need for family planning among women. As discussed above, the focus of policies and programs should be on spacing methods. It is also imperative to focus on disadvantaged groups such as Non-Hindu, Scheduled tribe, adolescent and poor women. Males should be involved in the counselling because large proportion of women indicated that their partner denied the use of contraception. Considering this fact, family planning program in Bihar should also focus on eliminating misconceptions and fear about contraception through proper counselling of couples and information, education and communication activities in the community and try to improve the quality of advice and care services related to family planning.

\section{Funding: No funding sources \\ Conflict of interest: None declared \\ Ethical approval: Not required}

\section{REFERENCES}

1. Bongaarts $\mathbf{J}$, Bruce $\mathbf{J}$. The causes of unmet need for contraception and the social content of services. Studies Fam Plann. 1995 Mar 1;26:57-75.

2. Westoff CF. Measuring the unmet need for contraception: comment on Bongaarts. Population Dev Rev. 1992 Mar;18(1):123-5.

3. Bankole A, Hussain R, Sedgh G, Rossier C, Kaboré I, Guiella G. Unintended pregnancy and induced abortion in Burkina Faso: Causes and consequences. Guttmacher Institute, New York. 2014 Dec.

4. Okonofua FE, Odimegwu C, Ajabor H, Daru PH, Johnson A. Assessing the prevalence and determinants of unwanted pregnancy and induced abortion in Nigeria. Studies Fam Plann. 1999 Mar;30(1):67-77.

5. Health Policy Initiative. Family planning and the MDGs: Saving lives, saving resources. Futures Group International. Washington, DC. Available at http://www. healthpolicyinitiative. com/Publications/Documents/788_1_Family_Planni ng_and_the_ MDGs_FINAL_June_09_acc. pdf. 2009.

6. Sedgh G, Hussain R, Bankole A, Singh S. Women with an unmet need for contraception in developing countries and their reasons for not using a method. Occasional report. 2007 Jun;37:5-40.

7. United Nations, Department of Economic and Social Affairs, Population Division. World Population Prospects: The 2017 Revision, Key Findings and Advance Tables. Working Paper No. ESA/P/WP/248. 2017. Available at 
https://esa.un.org/unpd/wpp/Publications/Files/WPP 2017_KeyFindings.pdf

8. Wilson C. On the scale of global demographic convergence 1950-2000. Population Development Rev. 2001;27:155-71.

9. IIPS. National Family Health Survey 4 fact sheet (2015-16). Available at http://rchiips.org/nfhs/ districtfactsheet_NFHS-4.shtml.

10. Sibanda A, Woubalem Z, Hogan DP, Lindstrom DP. The proximate determinants of the decline to belowreplacement fertility in Addis Ababa, Ethiopia. Studies Fam Plann. 2003 Mar;34(1):1-7.

11. Karki YB, Krishna R. Factors responsible for the rapid decline of fertility in Nepal--an interpretation. Further analysis of the 2006 Nepal Demographic and Health Survey. Calverton, MA: Macro International Inc. 2008.

12. Bongaarts J, Frank O, Lesthaeghe R. The proximate determinants of fertility in sub-Saharan Africa. Population Dev Rev. 1984 Sep 1:511-37.

13. Westoff CF. The potential demand for family planning: A new measure of unmet need and estimates for five Latin American countries. Int Fam Plann Perspect. 1988;14:45-53.

14. Bertrand G. Simple points, topological numbers and geodesic neighborhoods in cubic grids. Pattern Recognition Letters. 1994 Oct 1;15(10):1003-11.

15. Blanc AK, Curtis SL, Croft TN. Does contraceptive discontinuation matter? Quality of care and fertility consequences. Chapel Hill: Measure Evaluation, Carolina Population Center, University of North Carolina at Chapel Hill;1999

16. Bruce J. Fundamental elements of the quality of care: A simple framework. Stud Fam Plann. 1990;21:6191.

17. Jain A, Bruce J, Mensch B. Setting standards of quality in family planning programs. Stud Fam Plann. 1992 Nov 1;23(6):392-5.

18. Koenig Michael A, Hossain MB, Whittaker M. Does quality of care influence contraceptive use. Stud Fam Plann. 1997;28(4):278-89.

19. Magnani RJ, Hotchkiss DR, Florence CS, Shafer LA. The impact of the family planning supply environment on contraceptive intentions and use in Morocco. Stud Fam Plann. 1999 Jun;30(2):120-32.

20. RamaRao S, Lacuesta M, Costello M, Pangolibay B, Jones $\mathrm{H}$. The link between quality of care and contraceptive use. International family planning perspectives. 2003 Jun 1;29:76-83.

21. Bongaarts J. The KAP-gap and the unmet need for contraception. Population and development review. 1991 Jun 1;17:293-313.

22. Westoff CF, Ochoa LH. Unmet need and the demand for family planning. Institute for Resource Development, Macro International. 1991;5.

23. Radha Devi D, Rastogi SR, Retherford RD. Unmet need for family planning in Uttar Pradesh, National Family Health Survey Subject Reports No. 1.
Mumbai: International Institute for Population Sciences. 1996.

24. Registrar General of India and Census commissioner Census of India. Provisional population totals series 2011. New Delhi: Ministry of Home Affairs, Government of India;2011. Available at http://censusindia.gov.in/2011-provresults/data_files/india/pov_popu_total_presentation _2011.pdf

25. Anselin L. Local indicators of spatial association LISA. Geographical Analysis. 1995;27:93-115.

26. Guo G, Zhao H. Multilevel modeling for binary data. Annual Rev Sociol. 2000;26:441-62.

27. Di Prete TA, Forrostal JD. Multilevel models: methods and substance. Annual Review of Sociol. 1994;20:331-57.

28. Duncan C, Jones K, Moon G. Context, composition and heterogeneity: using multilevel models in health research. Social Sci Medic. 1998 Jan;46(1):97-117.

29. Diez-Roux AV. Bringing context back into epidemiology: variables and fallacies in multilevel analysis. Am J Public Health. 1998;88(2):216-22.

30. Korn EL, Graubard BI. Simultaneous testing of regression coefficients with complex survey data: Use of Bonferroni t statistics. Am Statistician. 1990 Nov;44(4):270-6.

31. Press SS. Stata statistical software: Release 10. College Station, TX: StataCorp LP. 2007.

32. Desktop EA. Release 10.2. 2. Redlands, CA, USA: Environmental Systems Research Institute. 2014.

33. Laya KS. Prevalence and determinants of unmet need for family planning among women in India. Res Soc Practices Soc Sci. 2012;7:59-70.

34. Bongaarts J. The KAP-gap and the unmet need for contraception. Population Dev Rev. 1991;17(2):293313.

35. Westoff CF. Is the KAP-gap real?. Population and development review. 1988 Jun 1;14(2):225-32.

36. Adebowale SA, Palamuleni ME. Determinants of unmet need for modern contraception and reasons for non-use among married women in rural areas of Burkina Faso. Afr Population Studies. 2014 Apr;28(1):499-514.

37. Kumar A, Singh A. Trends and determinants of unmet need for family planning in Bihar (India): evidence from National Family Health Surveys. Adv Appl Sociol. 2013;3(2):157-63.

38. Mishra VK, Retherford RD, Nair PS, Feeney G. Reasons for discontinuing and not intending to use contraception in India. NFHS Subject Report, No. 13, Mumbai: IIPS; 1999.

Cite this article as: Pal A, Yadav J, Sunita, Singh KJ. Factors associated with unmet need of family planning in Bihar, India: a spatial and multilevel analysis. Int J Reprod Contracept Obstet Gynecol 2018;7:3638-45. 